\title{
Masson's tumor of the pineal region: case report
}

\author{
Lefko T. Charalambous, BS, ${ }^{1}$ Anirudh Penumaka, BS, ${ }^{1}$ Jordan M. Komisarow, MD, ${ }^{1}$ \\ Amanda C. Hemmerich, MD, ${ }^{2}$ Thomas J. Cummings, MD, ${ }^{2}$ Patrick J. Codd, MD, ${ }^{1}$ and \\ Allan H. Friedman, MD'
}

\begin{abstract}
Departments of ${ }^{1}$ Neurosurgery and ${ }^{2}$ Pathology, Duke University Medical Center, Durham, North Carolina
Intracranial intravascular papillary endothelial hyperplasia (IPEH), also referred to as Masson's tumor, is a condition that rarely occurs in the nervous system. IPEH most frequently occurs extracranially in the skin of the face, skull, neck, and trunk and can easily be mistaken clinically, radiologically, and histologically for angiosarcoma, organizing hematoma, or other vascular malformations. IPEH accounts for roughly $2 \%$ of all vascular tumors and is extremely rare intracranially, with only 23 reported cases compared with more than 300 cases of IPEH occurring in the skin and subcutaneous tissue. To date, it has never been reported to occur in the pineal region. The authors report the case of a patient with an IPEH in the pineal region who underwent complex resection and experienced reversal of neurological symptoms.
\end{abstract}

https://thejns.org/doi/abs/10.3171/2017.2.JNS162350

KEY WORDS intravascular papillary endothelial hyperplasia; IPEH; Masson's tumor; intracranial tumor; vascular lesions; hemangioma; malignant angiosarcoma; oncology

I NTRAVASCULAR papillary endothelial hyperplasia (IPEH) is a benign proliferation of nonneoplastic, reactive endothelial cells often associated with organizing intravascular thrombi. The lesion commonly occurs in the space of existing vessels, vascular malformations, or organizing hematomas..$^{10,13,19,21,22}$ Intracranial IPEH has been reported in the skull base, sellar regions, and the petrous part of the temporal bone, but never the pineal region. 5,13,14,22,24 Extracranial IPEH is typically found in skin and subcutaneous tissues of the extremities; however, IPEH also presents at other locations, including the head, neck, and trunk, ${ }^{20,24}$ and in visceral organs. ${ }^{13,21,22}$ About $2 \%$ of all vascular tumors and subcutaneous lesions of the head, neck, and extremities are classified as IPEH.$^{15}$ While there have been more than 300 cases of extracranial IPEH, only 23 intracranial cases have been reported.,22 The lesion can be difficult to distinguish from other malignant or benign vascular tumors or malformations, such as angiosarcoma, angiomatous meningioma, cavernous hemangioma, arteriovenous angioma, and capillary hemangioma. ${ }^{8,13}$ Extracranial IPEH typically manifests as a slow-growing painful nodule, while intracranial IPEH may lack specific clinical symptoms and instead manifest with mass effects or neurological deficits reflecting its anatomical location. ${ }^{21}$ Previously reported patients with intracranial IPEH have presented with headaches, cranial neuropathies, visual deficits, seizures, increased intracranial pressure, and other location-specific mass effects..$^{5,9,13,21,22}$ We report the case of a 22-year-old man who presented with headaches, attention deficits, and memory deficits. Imaging studies revealed a vascular lesion in the pineal region that recurred as a Masson tumor and was successfully treated by resection. To our knowledge, this is the first reported case of an IPEH occurring in this region.

\section{Case Report}

History and Examination

A 22-year-old man presented to our emergency department complaining of a 2 -week history of headaches, difficulty with attention, and mild short-term memory disturbances.

The patient's neurological examination revealed no focal deficits. An MRI study of the brain with and without Gd contrast (Fig. 1) identified a $2.9 \times 3.4-\mathrm{cm}$ heterogeneously enhancing mass in the pineal region, with a central cystic component and mass effect on the superior peduncle, midbrain, and corpus callosum. There was no evidence of hydrocephalus or ventriculomegaly. Our differential diagnosis included the usual tumors that occur in the pineal area and we suspected a germ cell pathology. For this reason, a stereotactic biopsy was undertaken with the assistance of a CRW (Radionics) frame. Biopsy of the mass revealed acellular debris and fibrin without clear

ABBREVIATIONS IPEH = intravascular papillary endothelial hyperplasia.

SUBMITTED September 7, 2016. ACCEPTED February 9, 2017.

INCLUDE WHEN CITING Published online August 4, 2017; DOI: 10.3171/2017.2.JNS162350. 

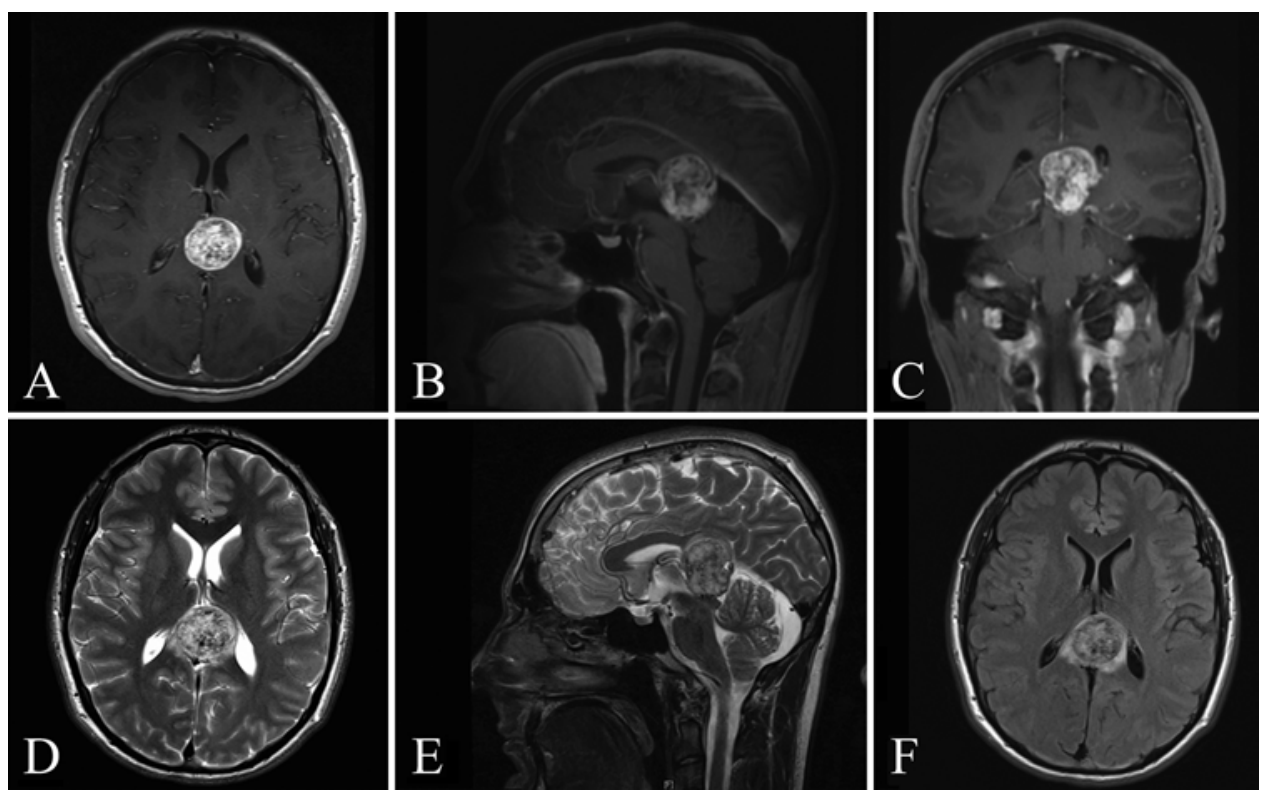

FIG. 1. Axial (A), sagittal (B), and coronal (C) Gd-enhanced T1-weighted; axial (D) and sagittal (E) T2-weighted; and axial FLAIR (F) MR images obtained at initial presentation, demonstrating a $2.9 \times 3.4-\mathrm{cm}$ high-density heterogeneously enhancing mass arising from within the pineal region, with mass effect on the lateral ventricle atrium, superior peduncle, midbrain, and corpus callosum.

pathological diagnosis, and thus a suboccipital craniotomy was performed.

\section{Operation}

Thrombocytopenia was noted at the time of admission. A workup by the hematology service failed to reveal the source of the thrombocytopenia, and findings on a preoperative angiogram were unremarkable. A suboccipital craniotomy with partial debulking via the supracerebellar subtentorial route was subsequently performed (Fig. 2). Pathology demonstrated a proliferation of capillaries; thin, dilated vascular channels; calcifications; and exuberant smooth-muscle and fibrocollagenous tissue, compatible with a vascular malformation with features suggestive of IPEH. We initially suspected that the lesion was a thrombosed vein of Galen vascular malformation. The patient's postoperative course was uneventful. In the setting of known thrombocytopenia, the patient also underwent bone marrow biopsy postresection, the findings of which were inconclusive for the cause of thrombocytopenia.

\section{Tumor Progression}

Approximately 4 months postoperatively, the patient's condition significantly worsened. He developed bitemporal headaches and profound short-term memory difficulties, and he was somewhat obtunded. MRI demonstrated tremendous enlargement of the heterogeneously enhancing lesion in the region of the pineal mass $(5.8 \times 4.6 \mathrm{~cm})$, now larger and lobulated, with a cystic anterior right portion measuring $2.7 \times 3.1 \mathrm{~cm}$ (Fig. 3). Due to the significant mass enlargement, diagnostic cerebral angiography was performed to further elucidate arterial and venous architecture and allow for surgical planning. The angiogram revealed subtle arterial vascular blush coming from bilateral pericallosal arteries as well as from the posterior cerebral artery. The deep veins were not visualized. The patient was again noted to be thrombocytopenic and, under guidance from the hematology service, was administered platelets (intravenous administration of immunoglobulin $1 \mathrm{~g} / \mathrm{kg}$ twice). The patient was admitted for resection.
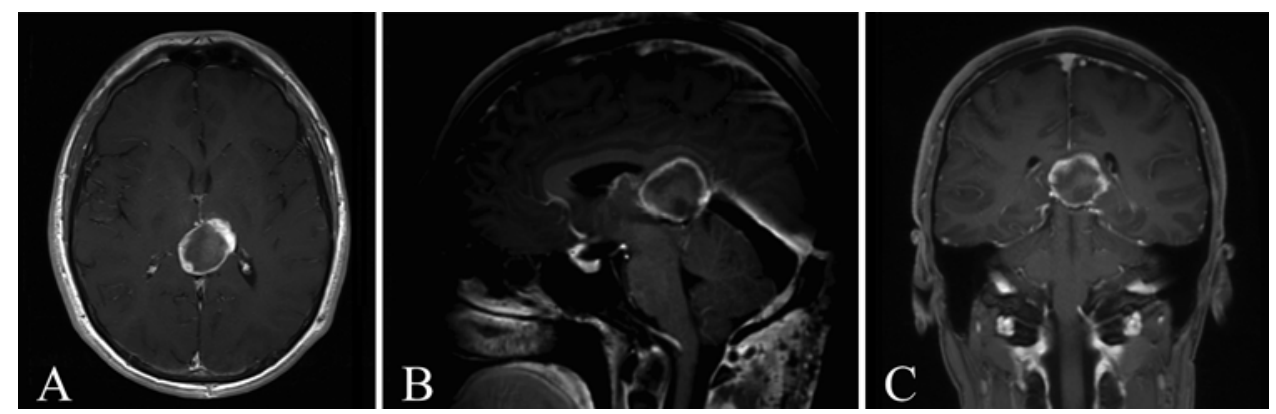

FIG. 2. Axial (A), sagittal (B), and coronal (C) T1-weighted postcontrast MR images obtained after suboccipital craniotomy for tumor debulking. 

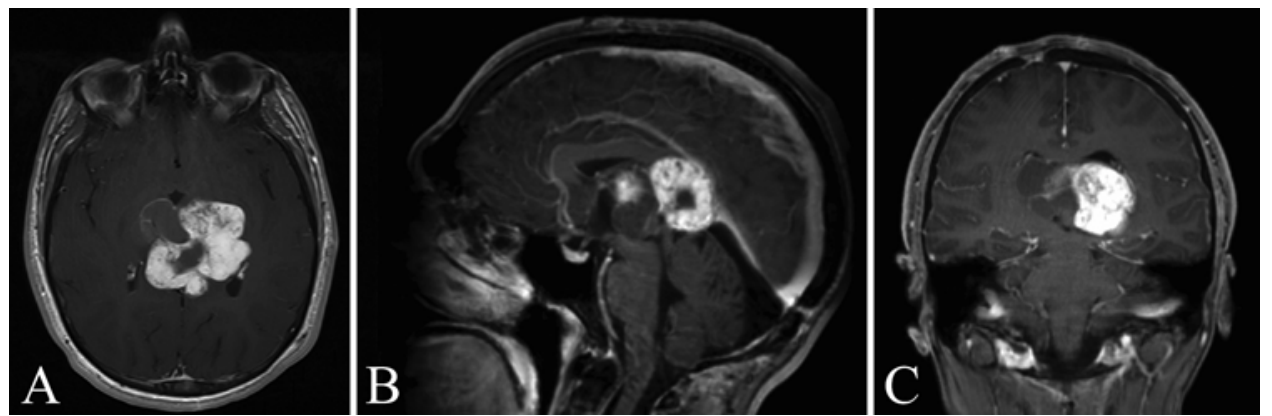

FIG. 3. Axial (A), sagittal (B), and coronal (C) T1-weighted postcontrast MR images showing tumor progression approximately 4 months after initial debulking. The images demonstrate enlargement of the heterogeneously enhancing lesion in the region of the pineal mass.

\section{Second Operation}

Given the progressive size of this lesion and worsening symptoms, the patient was taken to the operating room for resection of the lesion via a right occipitoparietal craniotomy with a right parietooccipital interhemispheric approach with cutting of the tentorium and falx. The vein of Galen and internal cerebral veins were noted to be displaced and

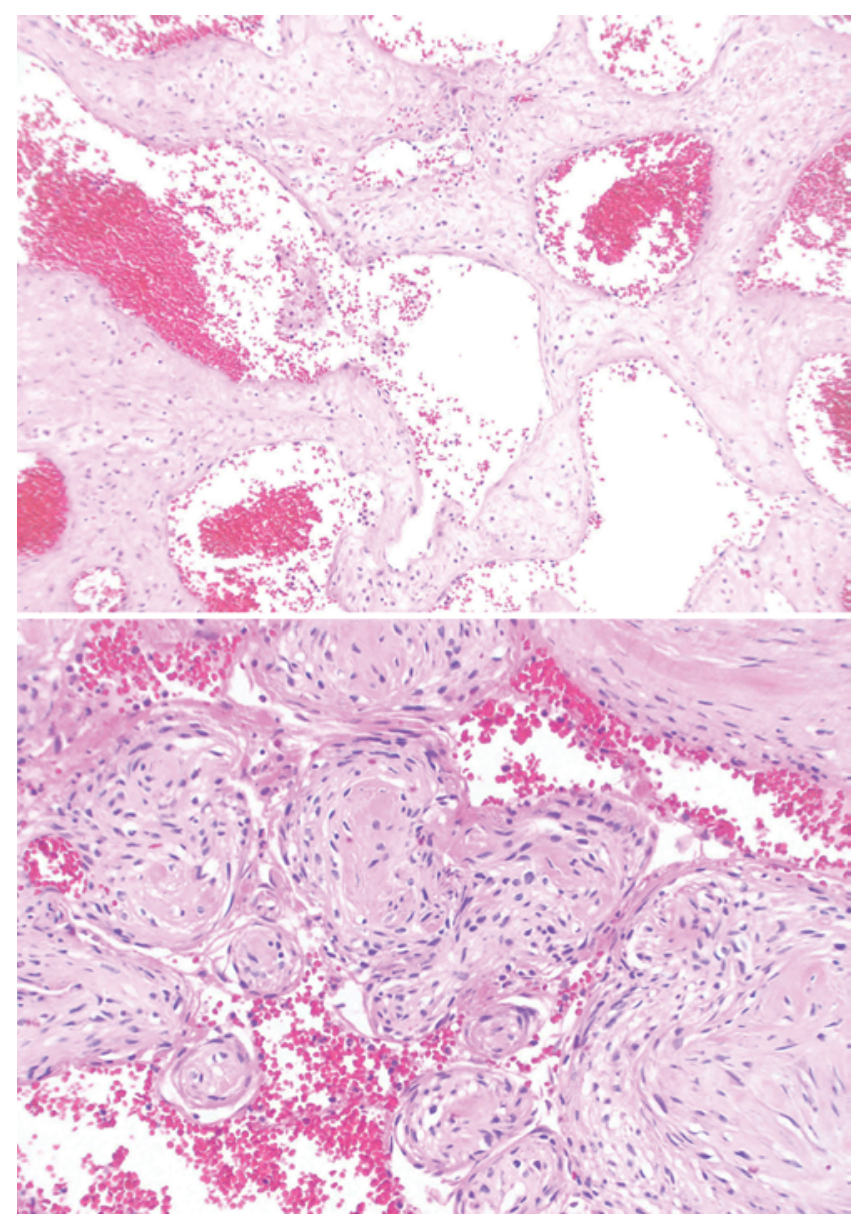

FIG. 4. Photomicrographs. Upper: The tumor is a vascular malformative lesion with a prominent smooth-muscle mesenchymal stroma. Lower: Multiple areas of the tumor show features of intravascular papillary endothelial hyperplasia. H\&E, original magnification $\times 10$ (upper); $\times 20$ (lower). Figure is available in color online only. not incorporated into the lesion. Findings on pathologic evaluation of this tissue were identical to those of the initial biopsy and demonstrated a vascular malformation-like proliferation of numerous large and dilated vascular channels, an exuberant smooth-muscle proliferation extending into the lumen of vessels, and formations typical of papillary endothelial hyperplasia (Fig. 4). While the diagnosis is readily made on findings from the $\mathrm{H} \& \mathrm{E}$-stained slides, additional studies were reviewed. Immunohistochemical stains for Masson trichrome, elastic fibers, and reticulin showed the stroma to be collagen rich and reticulin rich. Immunohistochemical stains for vascular markers, including CD31, CD34 (Fig. 5), and factor VIII, highlighted the endothelial cells. The stromal spindle cells were immunopositive for $\alpha$-smooth muscle actin and vimentin. Glial fibrillary acidic protein, cytokeratin, synaptophysin, S100 protein, placental alkaline phosphatase, and neurofilament protein were immunonegative. The MIB-1 index was low, approximately $2 \%$ overall (focally up to $5 \%$ ), and mostly reacted with the endothelial cells and not the smooth-muscle and fibrocollagenous tissue (Fig. 6). Despite the rapid growth of the lesion, there was no evidence of a malignant tumor. It is known that vascular malformative lesions can sometimes exhibit biologically aggressive clinical be-

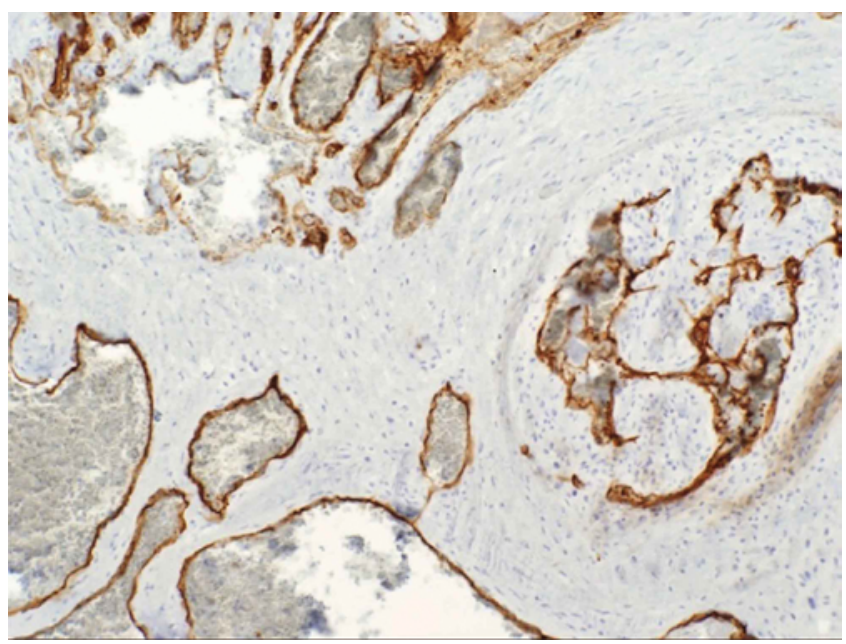

FIG. 5. CD34 immunohistochemical stain highlighting endothelial cells in the vascular channels. Original magnification $\times 10$. Figure is available in color online only. 


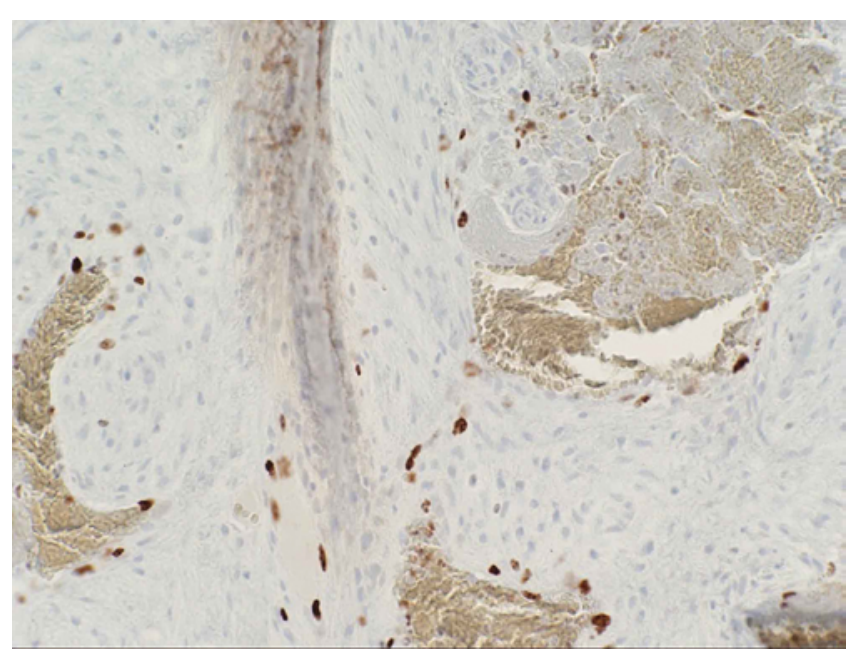

FIG. 6. MIB-1 immunohistochemical staining is low and evident mostly in endothelial cells and not smooth-muscle cells. Original magnification $\times 20$. Figure is available in color online only.

havior. Thus, the pathological findings were diagnostic of Masson's tumor, otherwise described as intravascular papillary endothelial hyperplasia.

\section{Second Postoperative Course}

After the second resection, the patient's postoperative course was uncomplicated. He was treated with high-dose steroids and several platelet transfusions. Three days postoperatively, the patient remained confused but had no new neurological deficits. Seven days postoperatively, the patient was discharged to a rehabilitation facility. MRI demonstrated complete resection of the tumor (Fig. 7), and no adjuvant therapy was deemed necessary.

\section{Rehabilitation}

At the time of discharge, the patient was able to ambulate independently with occasional unsteadiness. He continued to experience severe short-term memory deficits, language deficits, and visual disorganization. Over the next several months, the patient made significant gains in shortterm memory and was able to travel independently. Moreover, the patient's thrombocytopenia resolved, with platelet counts at 1,3, and 9 months postoperatively of greater than $130,000 / \mu 1$. Two years postoperatively, he returned to college studies. After 3 years of follow-up, MRI has demonstrated no recurrence of tumor.

\section{Discussion}

IPEH is an uncommon, but benign, reactive proliferation of endothelial growth that is often closely associated with organizing thrombotic material and bears a striking resemblance to hemangiosarcoma. Masson's tumor is now understood as a proliferative reaction to vascular trauma; ${ }^{12}$ however, debate remains as to whether IPEH is a response to thrombotic organization, the actual cause, or perhaps both. ${ }^{1,10,14,19,22}$ Although the pathogenesis of IPEH is still poorly understood, intracranial IPEH is thought to occur in association with preexisting vascular malformations, thrombi, aneurysms, hemangioma, pyogenic granuloma, phlebectasia, angiokeratomas, and lymphangiomas.,14,19 The proliferation of IPEH may occur in response to a combination of arterial and venous reorganization or leading to blood stasis and altered hemodynamic flow. Perturbed angiogenic factors and resultant chronic blood vessel inflammation lead to the proliferation of IPEH..$^{5,711,15}$ Thrombosis either acts as a matrix for endothelial cell proliferation ${ }^{10}$ or is the secondary consequence of the IPEH formation itself, without any prior thrombus or vascular defect..$^{19,22}$

Intracranial IPEH is exceedingly rare and can be associated with arteriovenous malformations, aneurysms, and cortical dysplasia. ${ }^{7}$ IPEH can occur in the skull base, the brain parenchyma, and the intravascular space of the skull. In their excellent review, Sim and colleagues described the location and outcomes of all previous cases of intravascular IPEH. ${ }^{22}$ Symptoms of intracranial IPEH include mass effects typical of space-occupying lesions, ${ }^{13,21}$ such as increased intracranial pressure and compression of adjacent neurovascular structures, hemorrhage,, 59 and cranial nerve palsies. ${ }^{22}$ A review of presentations in all previous cases based on the work of Sim et al.,22 in addition to the current case, is presented in Table 1. While there are previous reports of intracranial IPEH of the sellar and parasellar regions, posterior fossa, and other nearby areas, ${ }^{2,13-15,22}$ to our knowledge, our report represents the first intracranial IPEH of the pineal region. The patient's symptoms returned, and subsequent stereotactic biopsy identified intracranial IPEH of the pineal region. IPEH accounts for only $2 \%$ of vascular tumors of the head, neck, and extremities, ${ }^{15}$ making this case exceedingly rare.

On histology, IPEH appears as papillary projections of a hyalinized fibrous connective tissue core surrounded by a hyperplastic monolayer of endothelial cells. ${ }^{1}$ Endothelial cells in Masson's tumor may anastomose to form small-caliber vascular channels, indicative of IPEH. ${ }^{13,15}$ The lesion is almost always associated with an organizing thrombus, but there is some evidence that rather than a true neoplasm, IPEH is a reactive, abnormal organization of thrombus underlying hyperplastic endothelial proliferation. ${ }^{9}, 10,14$ The mass characteristically forms a pseudocapsule bordered by hemosiderin deposition..${ }^{15}$ Masson's tumor can be mistaken for other malignant neoplasms, such as angiosarcoma; ${ }^{15}$ however, key malignant features such as necrosis, nuclear pleomorphism, and infiltration are absent in IPEH. The diagnosis of IPEH can also be supported by immunohistochemical stains against endothelial cells, including factor VIII, CD31, and CD34. ${ }^{5,15}$

IPEH is often indistinct on imaging, and a biopsy is required for definitive characterization. On CT and MRI studies, the tumor is generally homogeneous and contrast enhancing..$^{13}$ T1-weighted images have shown the lesion varying from hypointense to isointense, while $\mathrm{T} 2$-weighted images display a hyperintense image., ${ }^{5,20}$ Gadoliniumenhanced images facilitate identification of the lesion and demonstrate the hyperdensity and hypervascularity of the mass. ${ }^{713} \mathrm{CT}$ imaging results can be variable, but the lesion generally appears hyperdense. ${ }^{5}$ Although localized radiographically, definitive diagnosis of IPEH is only possible with biopsy and histological examination..$^{20}$

IPEH should be included in the differential diagnoses of most vascular lesions of the skull base and intracranial compartment, especially when there is a history of vascu- 

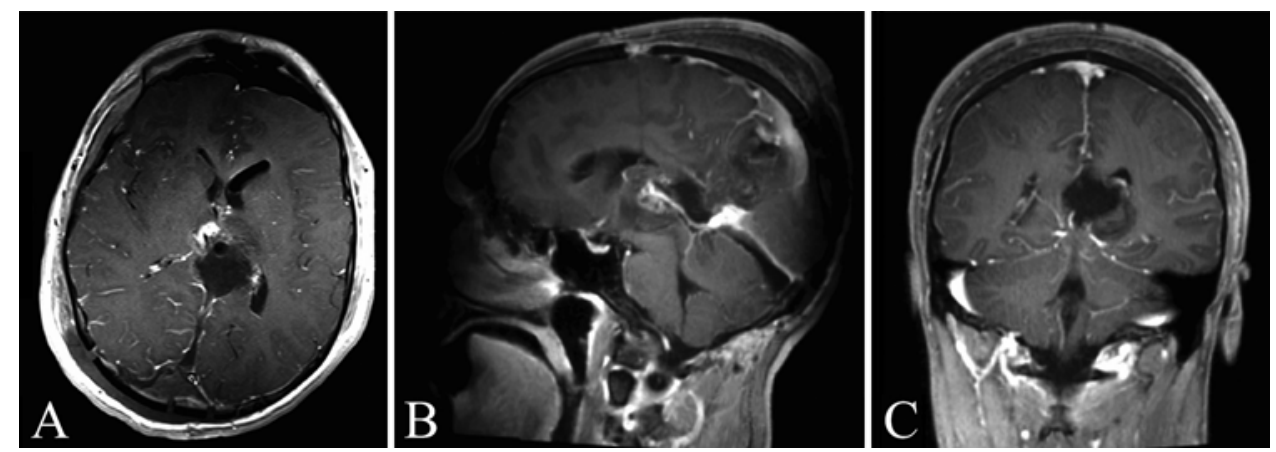

FIG. 7. Axial (A), sagittal (B), and coronal (C) T1-weighted postcontrast MR images obtained after resection, demonstrating grosstotal resection.

lar malformation. ${ }^{15}$ In contrast to vascular lesions, such as angiosarcoma, capillary hemangioma, cavernous hemangioma, and angiomatous meningioma, IPEH usually originates and is confined to the blood vessel lumen.,20 Differential diagnoses for IPEH include significantly more serious vascular neoplasms, such as malignant angiosarcoma. ${ }^{8,13-15,20,23}$ However, IPEH is generally considered benign, and complete resection of IPEH is curative. 5,13,15,21

A sufficient number of reports for a conclusive review of treatment options are lacking; however, gross-total resection, if possible, has been preferred and is generally considered curative. As in this patient, surgery can be complicated by thrombocytopenia. It is possible that thrombocytopenia is associated with IPEH in a Kasabach-Merritt type of phenomenon, ${ }^{6,14}$ which leads to localized consumption of platelets and coagulation activation, similar to the progression of chronic disseminated intravascular coagulation. Consistent with this theory, the patient's thrombocytopenia resolved after resection of the mass.

Of the 23 previously reported patients with intracra-

TABLE 1. Summary of symptoms at presentation in reported cases of IPEH*

\begin{tabular}{lcc}
\hline \multicolumn{1}{c}{ Presentation } & No. of Cases & \% Patients \\
\hline Headache & 6 & 25 \\
\hline Cranial nerve palsy & 6 & 25 \\
\hline Visual deficit & 6 & 25 \\
\hline Seizures & 5 & 21 \\
\hline Increased ICP & 3 & 13 \\
\hline Hemiparesis & 2 & 8 \\
\hline Proptosis & 2 & 8 \\
\hline Hearing loss & 2 & 8 \\
\hline Hydrocephalus & 1 & 4 \\
\hline Pituitary dysfunction & 1 & 4 \\
\hline Vertigo & 1 & 4 \\
\hline Gait disturbance & 1 & 4 \\
\hline Otalgia & 1 & 4 \\
\hline Dysphasia & 1 & 4 \\
\hline Memory/attention deficit & 1 & 4 \\
\hline
\end{tabular}

$\mathrm{ICP}=$ intracranial pressure

* Based on the review by Sim et al. of 23 patients and the findings in our patient. nial IPEH, gross-total resection without recurrence was achieved in $10 .^{22}$ Subtotal resection only could be performed in 12 of the remaining patients, with a recurrence rate of $42 \%(n=5) .{ }^{22}$ Due to the high risk for recurrence in cases of partial resection, most authors have recommended aggressive adjuvant therapy, such as radiotherapy, Gamma Knife radiosurgery, and chemotherapy. 3,7,13,16-18,20,22 Gamma Knife and stereotactic radiotherapy have been successful in terms of lesion stabilization and regression after incomplete resection or recurrence. ${ }^{7,15}$ While stereotactic and Gamma Knife radiosurgery have been the preferred methods, the outcomes of chemotherapy are less clear. ${ }^{20,25}$

In cases in which the risks of surgery as primary treatment of the lesion outweigh the benefits, Gamma Knife and stereotactic radiotherapy have been recommended. ${ }^{13-15}$ It should also be noted that some investigators have proposed a possible link between radiotherapy and the occurrence of IPEH, because of the obstruction of blood flow from the therapy. ${ }^{7}$ Importantly, this implication applies to any treatment that might disrupt blood flow or cause microemboli, and should be considered as a possible side effect of radiosurgery for any AVM.

\section{Conclusions}

IPEH is a benign, nonneoplastic endothelial proliferation. Intracranial cases are rare, but they are vitally important to consider in the differential diagnosis for intracranial lesions. IPEH is likely underreported because of short follow-up periods of approximately 12.8 months, despite the fact that they can recur more than 9 years after initial treatment. ${ }^{21,22}$ Masson's tumor is difficult to differentiate radiographically, requiring biopsy for diagnosis. Complete resection appears curative if achievable; incomplete resection can result in recurrence. Adjuvant therapy, such as radiotherapy, Gamma Knife radiosurgery, or chemotherapy, can be indicated but are not ideal treatment options. To our knowledge, this report is the first of IPEH of the pineal region that was successfully treated, with resection and with a good patient outcome.

\section{References}

1. Albrecht S, Kahn HJ: Immunohistochemistry of intravascular papillary endothelial hyperplasia. J Cutan Pathol 17:16-21, 1990 
2. Arnaout OM, Gross BA, Eddleman CS, Bendok BR, Getch CC, Batjer HH: Posterior fossa arteriovenous malformations. Neurosurg Focus 26(5):E12, 2009

3. Avellino AM, Grant GA, Harris AB, Wallace SK, Shaw CM: Recurrent intracranial Masson's vegetant intravascular hemangioendothelioma. Case report and review of the literature. J Neurosurg 91:308-312, 1999

4. Barr RJ, Graham JH, Sherwin LA: Intravascular papillary endothelial hyperplasia. A benign lesion mimicking angiosarcoma. Arch Dermatol 114:723-726, 1978

5. Cagli S, Oktar N, Dalbasti T, Işlekel S, Demirtaş E, Ozdamar $\mathrm{N}$ : Intravascular papillary endothelial hyperplasia of the central nervous system-four case reports. Neurol Med Chir (Tokyo) 44:302-310, 2004

6. Chen H: Kasabach-Merritt syndrome, in Atlas of Genetic Diagnosis and Counseling. Totowa, NJ: Humana Press, 2006, 563-566

7. Crocker M, deSouza R, Epaliyanage P, Bodi I, Deasy N, Selway R: Masson's tumour in the right parietal lobe after stereotactic radiosurgery for cerebellar AVM: case report and review. Clin Neurol Neurosurg 109:811-815, 2007

8. Duong DH, Scoones DJ, Bates D, Sengupta RP: Multiple intracerebral intravascular papillary endothelial hyperplasia. Acta Neurochir (Wien) 139:883-886, 1997

9. Hagiwara A, Inoue Y, Shakudo M, Wakasa K, Sato K, Ohata $\mathrm{K}$, et al: Intracranial papillary endothelial hyperplasia: occurrence of a case after surgery and radiosurgery. J Comput Assist Tomogr 23:781-785, 1999

10. Hashimoto H, Daimaru Y, Enjoji M: Intravascular papillary endothelial hyperplasia. A clinicopathologic study of 91 cases. Am J Dermatopathol 5:539-546, 1983

11. Henschen P: L'endovasculite proliferante thrombopoietique dans la lesion vasculaire locale. Ann Anat Pathol (Paris) 9:113-121, 1932

12. Hong SG, Cho HM, Chin HM, Park IY, Yoo JY, Hwang SS, et al: Intravascular papillary endothelial hyperplasia (Masson's hemangioma) of the liver: a new hepatic lesion. J Korean Med Sci 19:305-308, 2004

13. Kristof RA, Van Roost D, Wolf HK, Schramm J: Intravascular papillary endothelial hyperplasia of the sellar region. Report of three cases and review of the literature. J Neurosurg 86:558-563, 1997

14. Lesley WS, Kupsky WJ, Guthikonda M: Intravascular papillary endothelial hyperplasia arising within a posteroinferior cerebellar artery aneurysm: case report and review of the literature. Neurosurgery 47:961-966, 2000

15. Miller TR, Mohan S, Tondon R, Montone KT, Palmer JN, Zager EL, et al: Intravascular papillary endothelial hyperplasia of the skull base and intracranial compartment. Clin Neurol Neurosurg 115:2264-2267, 2013

16. Ohshima T, Ogura K, Nakayashiki N, Tachibana E: Intravascular papillary endothelial hyperplasia at the superior orbital fissure: report of a case successfully treated with Gamma Knife radiosurgery. Surg Neurol 64:266-269, 2005

17. Ong SS, Bruner J, Schellingerhout D, Puduvalli VK: Papillary endothelial hyperplasia presenting as recurrent malignant glioma. J Neurooncol 102:491-498, 2011

18. Park KK, Won YS, Yang JY, Choi CS, Han KY: Intravascu- lar papillary endothelial hyperplasia (Masson tumor) of the skull: case report and literature review. J Korean Neurosurg Soc 52:52-54, 2012

19. Requena L, Sangueza OP: Cutaneous vascular proliferation. Part II. Hyperplasias and benign neoplasms. J Am Acad Dermatol 37:887-922, 1997

20. Shah HC, Mittal DH, Shah JK: Intravascular papillary endothelial hyperplasia (Masson's tumor) of the scalp with intracranial extension. J Pediatr Neurosci 9:260-262, 2014

21. Shih CS, Burgett R, Bonnin J, Boaz J, Ho CY: Intracranial Masson tumor: case report and literature review. J Neurooncol 108:211-217, 2012

22. Sim SY, Lim YC, Won KS, Cho KG: Thirteen-year follow-up of parasellar intravascular papillary endothelial hyperplasia successfully treated by surgical excision: case report. J Neurosurg Pediatr 15:384-391, 2015

23. Stoffman MR, Kim JH: Masson's vegetant hemangioendothelioma: case report and literature review. J Neurooncol 61:17-22, 2003

24. Tedla M, Bežová M, Biró C, Tedlová E, Eng CY, Zeleník K: Intravascular papillary endothelial hyperplasia of larynx: case report and literature review of all head and neck cases. Otolaryngol Pol 68:200-203, 2014

25. Zhang R, Zhou LF, Mao Y, Wang Y: Papillary endothelial hyperplasia (Masson tumor) of the petrous and jugulare region: case report and literature review. Surg Neurol 64:5560,2005

\section{Disclosures}

The authors report no conflict of interest concerning the materials or methods used in this study or the findings specified in this paper.

\section{Author Contributions}

Conception and design: Charalambous, Penumaka. Acquisition of data: Hemmerich, Codd. Analysis and interpretation of data: Hemmerich. Drafting the article: Charalambous. Critically revising the article: Charalambous, Penumaka, Komisarow, Cummings, Codd, Friedman. Reviewed submitted version of manuscript: Charalambous, Penumaka, Komisarow, Cummings, Friedman. Approved the final version of the manuscript on behalf of all authors: Charalambous. Administrative/technical/material support: Charalambous, Komisarow, Codd, Friedman. Study supervision: Friedman.

\section{Supplemental Information \\ Previous Presentations}

A portion of this report was presented in an electronic poster format at the European Association of Neurosurgical Societies 2015 Annual Meeting, October 18-21, 2015, Madrid, Spain.

\section{Correspondence}

Lefko T. Charalambous, Department of Neurosurgery, Duke University Medical Center, 200 Trent Dr., PO Box 3807, Durham, NC 27710.email: 1tc7@duke.edu. 